\title{
LETTER TO THE EDITOR \\ Novel Mutations in the Von Hippel-Lindau Gene Associated with Congenital Polycythemia
}

To the editor: Polycythemia is a rare disorder in children and the vast majority of cases are secondary to causes such as cyanotic congenital heart disease, congenital lung diseases, liver and kidney disease, and masses producing erythropoietin. Mutations in exon 3 of the VHL gene are the most common cause of congenital erythrocytosis [1-3]. Several reports have shown evidence of heterozygous and homozygous mutations in exon 2 of the $V H L$ gene as a cause of congenital polycythemia [4-6].
We report on a 9-month-old female who was referred to the hematology clinic for evaluation by her pediatrician with plethora and erythrocytosis (RBC count $7.67 \mathrm{million} / \mathrm{mm}^{3}$, hemoglobin $21.5 \mathrm{~g} / \mathrm{dL}$, hematocrit $66.2 \%$, MCV $86.3 \mathrm{fL}$ ). The erythropoietin level was $48 \mathrm{IU} / \mathrm{L}$ (normal 4-27), in the face of marked erythrocytosis. The patient was started on phlebotomy treatments of $5 \mathrm{ml} / \mathrm{kg}$ of blood which has progressed to $10 \mathrm{ml} / \mathrm{kg}$ of blood with normal saline replacement every 4 weeks with good results. She was

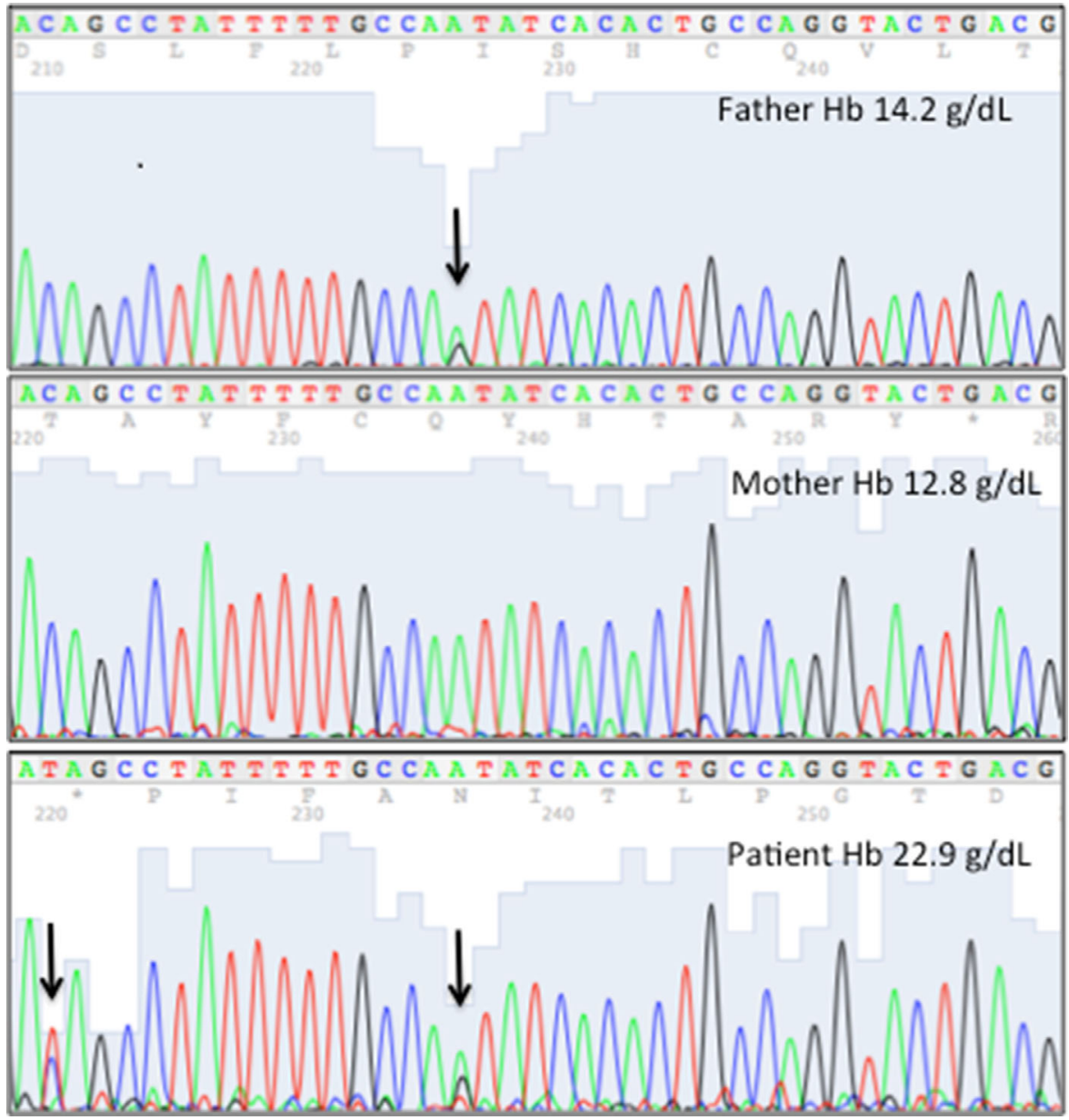

Fig. 1. Parental sequence analysis of exon 2 of the $V H L$ gene showed that the patient carries a paternally inherited c.662A $>\mathrm{G}$ (p.Asn $150 \mathrm{Ser}$ ) and a de novo c.646C $>\mathrm{T}$ (p.Gln145X) mutation (arrows). The hemoglobin levels are denoted in the sequence reads.

Conflict of interest: Nothing to declare.

${ }^{*}$ Correspondence to: Alpa Sidhu, Division of Genetics, Department of Pediatrics and Human Development, Michigan State University, 1355 Bogue Street, B-220B, East Lansing, MI, 48824. E-mail: alpa.sidhu@hc.msu.edu

Received 1 October 2014; Accepted 1 December 2014

(C) 2015 Wiley Periodicals, Inc.

DOI 10.1002/pbc.25407

Published online 13 January 2015 in Wiley Online Library

(wileyonlinelibrary.com). 
started on ferrous sulfate supplementation which continues till date for iron deficiency secondary to phlebotomy.

After a thorough evaluation for secondary causes of polycythemia ruled out cyanotic congenital heart disease, congenital lung diseases, liver or kidney disease, and masses producing erythropoietin, von Hippel-Lindau ( $V H L)$ gene sequencing analysis was performed. Our patient carries a paternally inherited [c.662A $>\mathrm{G}(\mathrm{p}$. Asn150Ser)] and a denovo (c.646C $>\mathrm{T}$ [p.Gln145X]) mutation, previously reported in VHL patients [7] (Fig. 1). In silico analysis using the NCBI HomoloGene tool for orthologous sequences for the $V H L$ gene shows the two residues to be conserved amongst species. The de novo mutation leads to a premature stop codon and is predicted to result in a non-functional protein. We believe the paternally inherited mutation (c.662A $>\mathrm{G}$ [p.Asn150Ser]) alters interaction of the VHL protein with HIF-2 alpha (HypoxiaInducible Factor) leading to clinical manifestations seen in the proband. The details of the interaction are outside the scope of the present report. VHL syndrome is a highly penetrant autosomal dominant disorder associated with tumors such as pheochromocytoma and hemangioblastomas of the retina, liver and cerebellum. To date, at age 9, our patient does not exhibit any of these manifestations. Patients with Chuvash polycythemia have frequent thrombotic events which have not been reported in either the proband or her father [6]. Previous reports have demonstrated mutations in exon 3 of the $V H L$ gene, including Chuvash polycythemia [8]. Few reports have shown both heterozygous and homozygous mutations in exon 2 of the $V H L$ gene leading to congenital polycythemia [4-6]. Our case adds to the present literature of growing evidence of exon 2 mutations, validating the importance of VHL mutational analysis in children as part of workup for congenital polycythemia. Based on our patient and previous reports, these exon 2 mutations do not seem to predispose either the proband or their carrier parents to an increased risk for
VHL-related tumors. Additional studies will be required to elucidate the molecular basis and genotype-phenotype correlation of these mutations that has a potential to greatly impact the surveillance guidelines for VHL-associated tumors.

\section{Alpa Sidhu MD, PhD* \\ Department of Pediatrics and Human Development, Division of Genetics, Michigan State University, East Lansing 48824, Michigan \\ Kanta Bhambhani MD, Michael U. Callaghan MD Department of Pediatrics, Division of Hematology, Wayne State University School of Medicine, Children's Hospital of Michigan, Detroit, Michigan}

\section{REFERENCES}

1. Pastore Y,Jedlickova K, Guan Y, Liu E, Fahner J, Hasle H, Prchal JF, Prchal JT. Mutations of von HippelLindau tumor-suppressor gene and congenital polycythemia. Am J Hum Genet 2003;73:412-419.

2. Ang SO, Chen H, Hirota K, Gordeuk VR, Jelinek J, Guan Y, Liu E, Sergueeva AI, Miasnikova GY, Mole D, Maxwell PH, Stockton DW, Semenza GL, Prchal JT. Disruption of oxygen homeostasis underlies congenital Chuvash polycythemia. Nat Genet 2002;32:614-621.

3. Pastore YD, Jelinek J, Ang S, Guan Y, Liu E, Jedlicko va K, Krishnamurti L, Prchal JT. Mutations in the VHL gene in sporadic apparently congenital polycythemia. Blood 2003;101:1591-1595.

4. Lanikova L, Lorenzo F, Yang C, Vankayalapati H, Drachtman R, Divoky V, Prchal JT. Novel homozygous VHL mutation in exon 2 is associated with congenital polycythemia but not with cancer. Blood 2013;121:3918-3924.

5. Bond J, Gale DP, Connor T, Adams S, de Boer J, Gascoyne DM, Williams O, Maxwell PH, Ancliff PJ Dysregulation of the HIF pathway due to VHL mutation causing severe erythrocytosis and pulmonary arterial hypertension. Blood 2011:117:3699-3701.

6. Sarangi S, Lanikova L, Kapralova K, Acharya S, Swierczek S, Lipton JM, Wolfe L, Prchal JT. The homozygous VHL(D126N) missense mutation is associated with dramatically elevated erythropoietin levels, consequent polycythemia, and early onset severe pulmonary hypertension. Pediatr Blood Cancer 2014;61:2104-2106.

7. Glasker S, Bender BU, Apel TW, Natt E, van Velthoven V, Scheremet R, Zentner J, Neumann HP. The impact of molecular genetic analysis of the VHL gene in patients with haemangioblastomas of the central nervous system. J Neurol Neurosurg Psychiatry 1999:67:758-762.

8. Gordeuk VR, Sergueeva AI, Miasnikova GY, Okhotin D, Voloshin Y, Choyke PL, Butman JA, Jedlickova K, Prchal JT, Polyakova LA. Congenital disorder of oxygen sensing: Association of the homozygous Chuvash polycythemia VHL mutation with thrombosis and vascular abnormalities but not tumors. Blood 2004;103:3924-3932. 